\title{
Expression of con genes along the three sporulation pathways of Neurospora crassa
}

\author{
Matthew L. Springer ${ }^{1}$ and Charles Yanofsky \\ Department of Biological Sciences, Stanford University, Stanford, California 94305 USA
}

\begin{abstract}
The filamentous fungus Neurospora crassa produces three types of spores by using different developmental pathways: macroconidiation, microconidiation, and sexual spore (ascospore) formation. Several genes of unknown function have been cloned by virtue of their expression during macroconidiation but not during mycelial growth (con genes). It had been postulated that expression of the con genes was specific to macroconidiation. To test this assumption, protein extracts from macroconidia, microconidia, ascospores, and protoperithecia (sexual structures) were analyzed for the product of one of the con genes, con-10, by immunoblotting using a CON10-specific antiserum. CON10 was detected in all of these extracts. An immunologically related protein was detected in an extract from ascospores of a nonconidiating Neurospora species, $N$. africana. Total RNA isolated from the three types of $N$. crassa spores was analyzed for con gene mRNA by Northern blotting using five different con genes as probes. Transcripts for four of the genes were detected in all three spore types; mRNA for the fifth gene was detected in macroconidia and microconidia but not in ascospores. Analysis of aconidial and female sterile mutants showed that expression of the con genes along any one developmental pathway occurs when expression along another pathway is genetically blocked.
\end{abstract}

[Key Words: Neurospora crassa; developmental regulation; conidia; microconidia; ascospores]

Received January 27, 1992; revised version accepted March 17, 1992.

The fungus Neurospora crassa grows vegetatively as filamentous hyphae that fuse together to form a mycelium. When a mycelium is deprived of nutrients, it produces three different types of reproductive spores. The prevalent class of spores in wild-type cultures, macroconidia, arise through a process of repeated apical budding of specialized aerial hyphae (Selitrennikoff et al. 1974; Springer and Yanofsky 1989). Production of these multinucleate spores endows the organism with an extremely efficient dispersal mechanism for asexual reproduction; disturbance of a typical laboratory culture is sufficient to disperse $\sim 10^{9}$ conidia into the air, where they may remain for several minutes before settling (Davis and de Serres 1970). When cultures age, microconidiation occurs directly from cells of the mycelial hyphae by a morphological process distinct from macroconidiation (Dodge 1932; Grigg 1960). Microconidia are smaller than macroconidia and are uninucleate. They do not possess an efficient dispersal mechanism and are less viable than macroconidia. $N$. crassa can also enter a sexual reproductive pathway that is specifically activated by nitrogen starvation when growth is on solid medium (Ricci et al. 1991). Activation of this pathway is dependent on the presence of cells of both mating types (Bistis 1981). This pathway involves the production of protoperithecia, sexual structures of one mating type that, when fertilized by

'Present address: Department of Biochemistry, Stanford University Medical Center, Stanford, California 94305 USA. cells of the opposite mating type, develop into mature perithecia that forcibly eject ascospores, the haploid products of meiosis, into the air (Harris et al. 1975; Raju 1980).

The con (conidiation) genes were isolated as subjects for studies on developmental gene regulation on the basis of differential expression during the asexual life cycle (Berlin and Yanofsky 1985). These genes encode mRNAs that are present at higher levels during macroconidiation than during vegetative mycelial growth. The products of two of the con genes have been localized to macroconidia within a conidiating culture (Springer et al. 1992|. In addition, mutants selected on the basis of con gene expression during mycelial growth are generally defective in macroconidiation (D. Ebbole and C. Yanofsky, in prep.; B. White and C. Yanofsky, in prep.). Because the macroconidiation developmental pathway is distinct from other sporulation pathways in $N$. crassa, it was postulated that con gene expression was specific to macroconidiation (Roberts et al. 1988; Roberts and Yanofsky 1989; Hager and Yanofsky 1990). Here, we present evidence that at least four con genes are also expressed during microconidiation and during protoperithecium and ascospore formation. We also show that expression of these genes along any of the developmental pathways proceeds in mutants blocked in one of the other pathways. In addition, we show that a protein immunologically similar to the product of con-10 is present in ascospores of the related nonconidiating species Neurospora 
africana but is not detectable in the more distantly related conidial fungus Aspergillus nidulans or in the dimorphic yeast Candida albicans.

\section{Results and discussion}

Presence of CON10 protein in other developmental structures, strains, and species

The three $N$. crassa sporulation pathways differ appreciably from one another; the spores arise by completely different processes that involve clearly distinguishable morphological intermediates (Fig. 1). Macroconidiation proceeds by a process involving repeated apical budding of the cells of specialized aerial hyphae, followed by cross-wall formation and subsequent separation of the buds into multinucleate macroconidia (Fig. 1a) (Turian and Bianchi 1972; Selitrennikoff et al. 1974; Springer and Yanofsky 1989|. Microconidiation involves the production of spores within normal mycelial cells (Fig. 1b) (Dodge 1932; Grigg 1960). Unlike formation of macroconidia, the smaller, uninucleate microconidia are produced within the hyphae and rupture through the hyphal cell wall as independent morphological entities (Fig. 1c,d) (Lowry et al. 1967; Rossier et al. 1973). The sexual cycle is activated specifically by nitrogen starvation
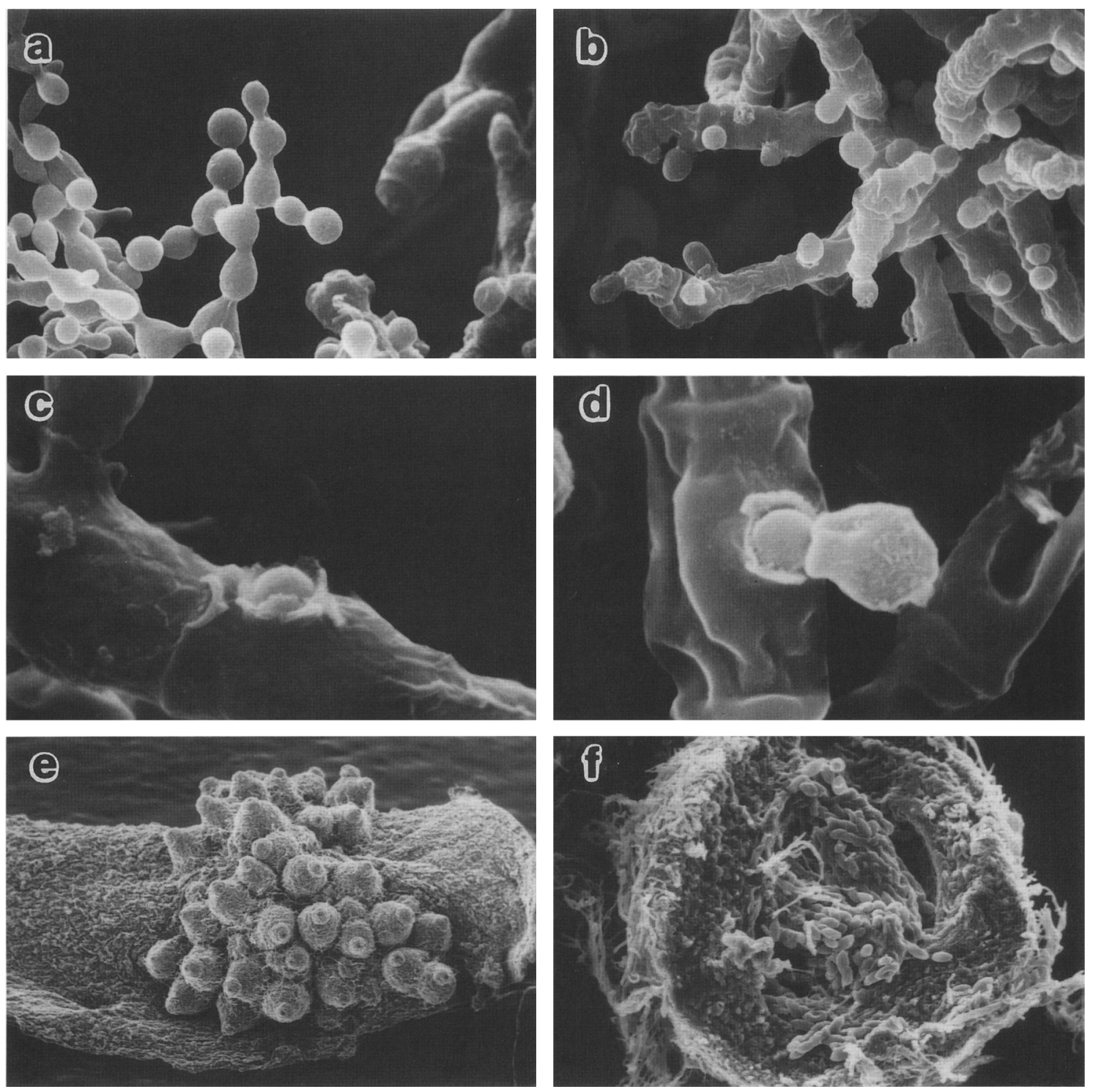

Figure 1. Scanning electron micrographs of macroconidiation $(a)$, microconidiation $(b-d)$, and sexual structures $(e, f)$. $(a)$ Macroconidiation by repeated apical budding from aerial hyphae (magnification, 1,200 $\times)$. (b) Microconidiation on mycelial hyphae (magnification, $2,700 \times)$. (c) Initial eruption of a microconidium through a hyphal cell wall (magnification, $11,000 \times$ ). (d) Second microconidium emerging (magnification, 10,000×). (e) Low-magnification of perithecia clumped on an agar surface (magnification, 16×). [Reprinted, with permission, from the cover of BioEssays $(1990)$ vol. 13, no. 2.] $(f)$ Perithecium sliced open with a razor blade to reveal asci containing ascospores (magnification, $120 \times$ ). 
(Ricci et al. 1991). Protoperithecia originate as tight knots of hyphae on the surface of the mycelium; they grow to $\sim 50 \mu \mathrm{m}$ in diameter and produce specialized hyphae, trichogynes, that function as recipients of fertilizing cells containing nuclei of the opposite mating type (Bistis 1981). The fertilized protoperithecia mature to become perithecia, which contain many asci with four pairs of ascospores, the products of meiosis (Fig. le,f) (Raju 1980; for a detailed scanning electron micrograph record of the sequence of events in perithecium and ascospore formation, see Harris et al. 1975). Ascospores are ultimately ejected forcibly from the perithecia through specialized pores.

Immunoblot analyses were performed with an antiserum directed against the protein product of the con-10 gene, CON10, an $8.5-\mathrm{kD}$ soluble protein that is present in macroconidia but not in mycelia (Roberts et al. 1988; Springer et al. 1992). Our objective was to determine whether the protein was present in different types of developmental structures or was macroconidiation specific, as was thought previously. Protein extracts were prepared from mature macroconidia of wild-type strain $74 \mathrm{~A}$ and a strain disrupted in con-10 and con-13 (con-10/ $13^{R I P}$; Springer et al. 1992), from microconidia of the macroconidiation-defective double mutant $f l ; d n$ (Wilson 1985), from mycelia containing protoperithecia of the aconidial mutant $f l$, and from ascospores of a $f 1 \times 74 \mathrm{~A}$ cross. To determine whether CON10 was present in related fungi, extracts from other species were also examined by immunoblot analysis. Extracts were prepared from ascospores of $N$. africana, which is a homothallic strain that does not conidiate (Mahoney et al. 1969); from conidia and mycelia of $A$. nidulans, which is a more distantly related conidial plectomycete that has also been shown to express conidiation-specific genes (Timberlake 1980); and from the yeast and mycelial forms of $C$. albicans, a dimorphic yeast with two modes of growth that bear a striking resemblance to Neurospora conidial budding and hyphal growth (Soll 1986).

The resulting immunoblots are shown in Figure 2. Equal amounts of protein were loaded in each lane. As expected, the CON10 protein was present in $74 \mathrm{~A}$ macroconidia and absent from con $-10 / 13^{R I P}$ macroconidia. Interestingly, CON10 was also present in microconidia, apparently in greater abundance than in macroconidia. CON10 was detected in some (Fig. 2b), but not all (Fig. 2a), protein extracts of mycelia containing protoperithecia. This variability probably can be attributed to the resiliency of protoperithecia and not to an actual lack of this protein. It was difficult to disrupt these dense hyphal balls reproducibly. They were ruptured in some preparations (based on microscopic examination) but not in others, whereas the mycelia in the samples were always disrupted. CON10 was detected in ascospores, but was present at a much lower level. The CON10 antiserum did not recognize a polypeptide of the CON10 size $(8.5 \mathrm{kD})$ in extracts of $N$. africana ascospores. However, the antiserum specifically recognized a polypeptide of $\sim 15 \mathrm{kD}$, which is approximately double the size of CON10; this protein was not detected in immunoblots in which preimmune serum was used as a primary antibody (data not shown). Mycelial extracts of $N$. africana were not examined. The $15-\mathrm{kD}$ protein may be an $N$. africana homolog of CON10; however, no evidence exists to confirm this. Protein extracts from Aspergillus (conidia and mycelia) and Candida (yeast and mycelia) did not contain any protein that was recognized by the CON10 antiserum (data not shown).

Despite the functional similarity of ascospores to macroconidia and microconidia, it can be argued that the truly analogous sexual structure is the protoperithecium, which is the direct end product of the sexual developmental pathway (in the absence of cells of the other mating type). Formation of protoperithecia, like that of asexual spores, is induced by nutrient deprivation. To determine whether the CON10 detected in the protoperithecial extract was actually formed in the surrounding mycelium in response to starvation, an extract was prepared from a culture that had been grown on crossing medium (nitrogen-starved) at $34^{\circ} \mathrm{C}$, a temperature that inhibits the formation of protoperithecia. Microscopic examination confirmed that no protoperithe-
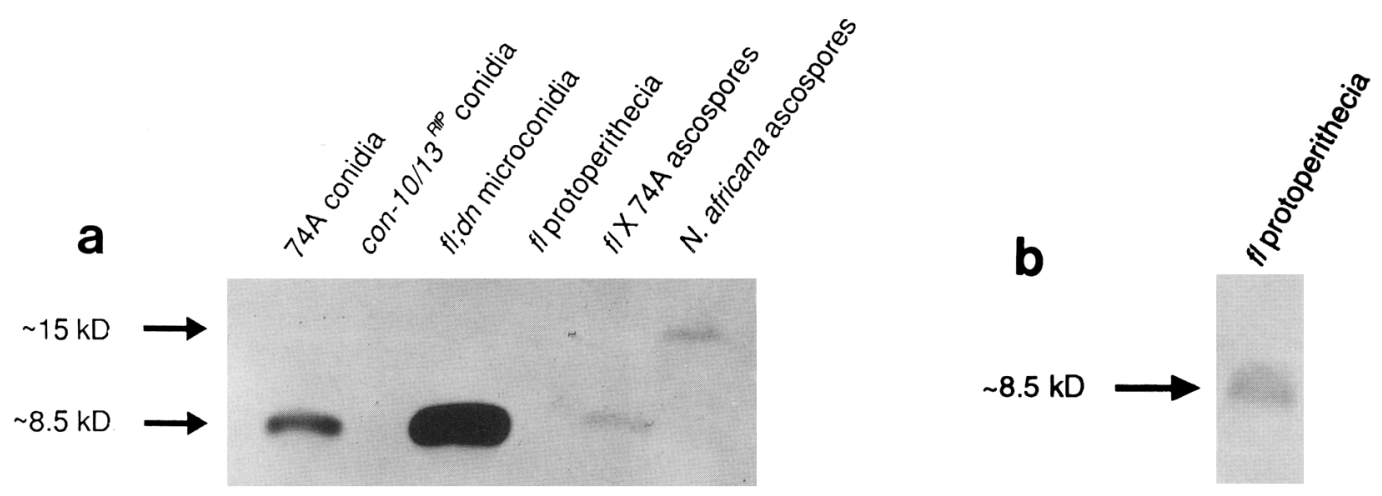

Figure 2. (a) Immunoblot showing CON10 protein in macroconidia, microconidia, and ascospores. Samples were electrophoresed in a tricine-SDS-polyacrylamide gel (Schägger and von Jagow 1987). The protein was absent from this protoperithecial extract but was present in some others (Fig. $2 \mathrm{~b}$; see text). A higher molecular weight polypeptide was detected in the $N$. africana ascospore lane. (b) Immunoblot showing CON10 protein in protoperithecia. 
cia, macroconidia, or microconidia were present in the culture. Immunoblot analysis showed that there was a small amount of CON10 detectable in the $34^{\circ} \mathrm{C}$ sample despite the absence of protoperithecia; CON10, however, was detectable at a higher level in samples containing protoperithecia (data not shown), implying that although crossing medium alone is capable of inducing low-level expression of con-10, the presence of moderate levels of $\mathrm{CON} 10$ is correlated with the presence of protoperithecia.

\section{Expression of con-10 in mutants blocked in different developmental pathways}

The findings presented in Figure 2 demonstrate that CON10 protein is present in microconidia and protoperithecia of $f l$, a strain that is genetically blocked at an early stage of macroconidiation (Springer and Yanofsky 1989). Furthermore, a protein immunologically related to CON10 is present in the aconidial species, N. africana. These observations establish that CON10 is produced in the microconidiation and sexual reproductive pathways regardless of the ability of a strain to produce macroconidia. The reciprocal experiment was performed to determine whether a defect in the formation of protoperithecia would affect CONlO production during macroconidiation. Several mutations block the formation of protoperithecia. One, ff-1 (female-fertility-1) (Tan and Ho 1970), allows macroconidiation to proceed as usual. A protein extract made from macroconidia of this strain was shown by immunoblotting to contain a CON10 band (data not shown). Taken together, our results (Table 1) demonstrate that inability to complete a specific sporulation pathway does not prevent the synthesis of CON10 along a separate pathway. At present, no known mutants are defective in microconidiation.

\section{Expression of other con genes in different developmental pathways}

The presence of CON10 protein in microconidia, protoperithecia, and ascospores raises the possibility that other con genes are expressed along the microconidiation and sexual pathways as well. This possibility was examined by RNA blot analysis. Total RNA was prepared from macroconidia of $74 \mathrm{~A}$ and con-10/13 ${ }^{R I P}$, from microconidia of $\mathrm{fl}$; $d n$, from ascospores of a $\mathrm{fl} \times 74 \mathrm{~A}$ cross, and from mycelia of $74 \mathrm{~A}$ and $f 1 ; d n$. Equal amounts of RNA from each of these samples were electrophoresed, stained with ethidium bromide to confirm equal loading, transferred onto Nytran, and hybridized with DNA probes prepared from con- 6 , con-8, con-10, con-11, and con-13. The results obtained are shown in Figure 3. With the exception of con-13, for each con gene tested a strong RNA signal was detected in $74 \mathrm{~A}$ macroconidia. The con-13 mRNA band was very faint, as had been observed previously (K. Hager, unpubl.). con-10 and con-13 RNAs were undetectable in con-10/13 ${ }^{R I P}$ conidia, as was expected. All of the con gene transcripts were present at
Table 1. Summary of con-10 expression in sporulation-defective strains

\begin{tabular}{|c|c|c|}
\hline Strain/species & Defect & $\begin{array}{l}\text { Presence of CON } 10 \\
\text { protein }\end{array}$ \\
\hline$f l$ & lacks macroconidia & $\begin{array}{l}\text { CON10 protein } \\
\text { present in } \\
\text { microconidia, } \\
\text { protoperithecia }\end{array}$ \\
\hline N. africana & lacks macroconidia & $\begin{array}{l}\text { a } 15-\mathrm{kD} \text { protein } \\
\text { present in } \\
\text { ascospores } \\
\text { recognized by } \\
\text { CON10 antiserum }\end{array}$ \\
\hline$f f-1$ & lacks protoperithecia & $\begin{array}{l}\text { CON10 protein } \\
\text { present in } \\
\text { macroconidia }\end{array}$ \\
\hline
\end{tabular}

Results for $f l$ and $N$. africana are shown in Fig. 2. The ff- 1 result is discussed in the text. The findings summarized here establish that expression of con-10 along any of the sporulation pathways occurs in mutants blocked in the macroconidiation and sexual pathways.

high levels in microconidia except con-13 mRNA, which was present at a low level. In ascospores, con gene transcripts were detected at varying levels, except for the con-13 transcript, which was undetectable. The two mycelial samples contained little or no RNA for the con genes examined except for con-8, which was shown previously to be expressed in old mycelia (Roberts and Yanofsky 1989; Sachs and Yanofsky 1991). We are unable to explain why con-8 and con-11 transcripts were present in greater amounts in 74A mycelia and con-10 and con-13 transcripts were present in greater amounts in $f 1 ; d n$ mycelia. The con -10 and con -13 results may be due to the fact that $f l ; d n$, which microconidiates profusely on an agar surface, actually made some microconidia in the liquid mycelial culture as judged by microscopic examination.

It appears that at least four and possibly five con genes are expressed in developmental processes leading to the formation of the three types of spores of $N$. crassa. We do not know the function of these genes, as the disruption of some of them does not lead to a discernible mutant phenotype with regard to morphology, abundance of macroconidia and microconidia, conidial germination efficiency, and ability to function as either parent in sexual crosses (Springer et al. 1992). The presence of their products in the three types of $N$. crassa spores, however, is of interest because the corresponding developmental pathways involve considerably different morphological intermediates. The observation that some con gene transcripts are present in all three types of spores implies that their products are not used for a purpose unique to a single sporulation process. Their roles may be related to spore development, dormancy, or germination. The CON10 protein present in protoperithecia may be loaded into ascospores as they develop within the perithecium. This situation is similar to that observed in A. nidulans, in which certain genes, such as Spo28, which is ex- 


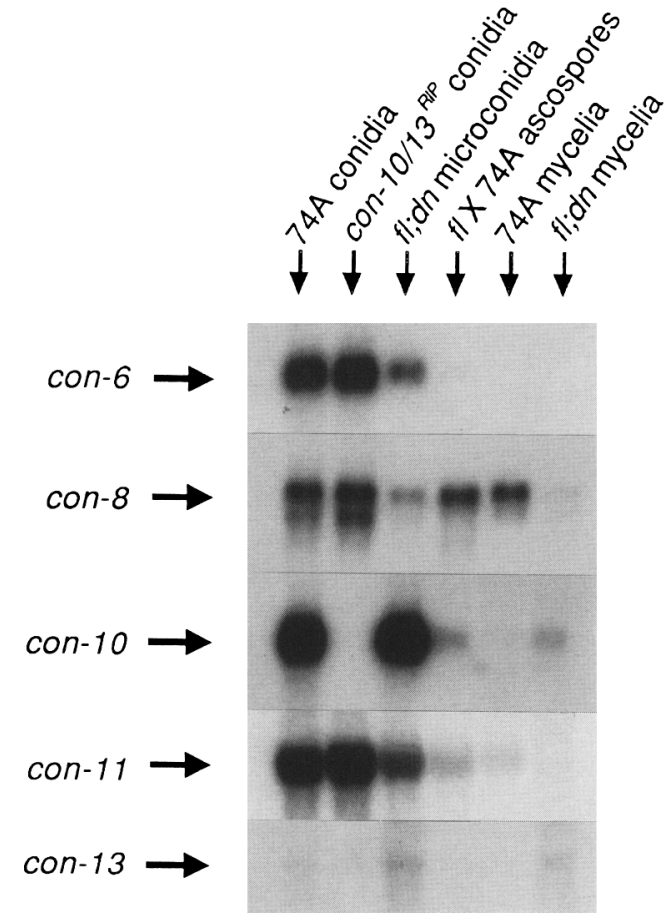

Figure 3. RNA blots showing the presence of con gene mRNA in different types of spores. RNA was electrophoresed on a $1.5 \%$ agarose denaturing formaldehyde gel (see Materials and methods). In this autoradiograph, the signals for con-10 in both macroconidia and microconidia are saturated. A shorter exposure time gives a higher signal for microconidia than for macroconidia, which is consistent with the corresponding protein levels; however, the shorter exposure time also gives inferior signals for ascospores and $f l$; $d n$ mycelia.

pressed during conidiation but not during mycelial growth, are also expressed in ascospores (Jurgenson and Champe 1990). An interesting difference is that Aspergillus mutants that fail to make conidia still produce ascospores that are devoid of Spo28, whereas the Neurospora con genes studied are still expressed in the other sporulation pathways when one pathway is blocked. Whatever their roles turn out to be, it is evident that some of the con genes are governed by regulatory processes that can be called upon in each developmental pathway independently of their activation along another pathway. Future studies on con gene regulation should provide insight into their mechanisms of regulation along the different developmental pathways.

\section{Materials and methods}

Strains and culture conditions

The wild-type strain used in this study was 74-OR23-1A. con$10 / 13^{R I P}$ (ES8:1) was provided by E. Selker (University of Oregon, Eugene, OR; Springer et al. 1992). $f 1^{P}, f l ; d n$, and $N$. africana were obtained from D.D. Perkins (Stanford University). A. nidulans (FGSC no. A89) was obtained from the Fungal Genetics Stock Center (University of Kansas Medical Center, Kansas
City). C. albicans 366 was a gift of C. Selitrennikoff (University of Colorado Health Sciences Center, Denver). Routine crosses and manipulations were performed as described by Davis and de Serres (1970) and Perkins (1986). Unless otherwise noted, the medium used was Vogel's minimal medium N (Vogel 1964); solid medium contained $1.5 \%$ agar. Crossing agar contained SC medium (Davis and de Serres 1970).

\section{Preparation of protein extracts and RNA}

For conidial protein extracts, conidia $\left(1 \times 10^{9}\right.$ to $\left.5 \times 10^{9}\right)$ were harvested from a 6-inch agar slant or from a 250 -ml Erlenmeyer flask culture grown on $50 \mathrm{ml}$ of agar solidified medium. For microconidial protein extracts, microconidia were harvested with water from a $250-\mathrm{ml}$ Erlenmeyer flask culture of $f 1 ; d n$ grown on $50 \mathrm{ml}$ of agar-solidified medium. Mycelia containing protoperithecia were obtained by growing $f l$ on a piece of Whatman 541 paper on the surface of crossing agar for 4 days at room temperature and then harvesting the mycelia by scraping the paper. Before scraping, the mycelia typically contained $\sim 5 \times 10^{3}$ protoperithecia $/ \mathrm{cm}^{2}$. For ascospore protein extracts from $N$. crassa and $N$. africana, ascospores were collected from the lid of a crossing plate. Aspergillus conidia were harvested from a culture grown on $200 \mathrm{ml}$ of solid Vogel's $\mathrm{N}$ medium in a 2800-ml Fernbach flask. Aspergillus mycelia were grown from a loopful of conidia in liquid Vogel's $\mathrm{N}$ medium for several days. Candida was grown in liquid sterile synthetic medium (SSM; Lee et al. 1975/ shaking at $200 \mathrm{rpm}$ overnight at $25^{\circ} \mathrm{C}$ for the yeast form and at $37^{\circ} \mathrm{C}$ for a mixture that contained mostly the mycelial form. Samples were disrupted in a mini-beadbeater (Biospec Products, Bartlesville, OK) using 0.5-mm glass beads in a buffer containing $50 \mathrm{~mm}$ Tris $(\mathrm{pH} 8.0), 1 \mathrm{~mm}$ EDTA, $1 \mathrm{~mm}$ PMSF, $100 \mu \mathrm{g} / \mathrm{ml}$ of leupeptin, and $0.02 \% \mathrm{NaN}_{3}$ at $4^{\circ} \mathrm{C}$. For most samples, one 2-min burst was used. Mycelial samples were subjected to two 2 -min bursts separated by $\sim 1$ min on ice. Protoperithecia were subjected to four 2-min bursts. In all cases, sample disruption was monitored using phase microscopy; intact cells were phase-light, whereas disrupted cells were phasedark.

Preparation of an antiserum directed against a TrpE-CON10 fusion protein and its use in immunoblot analyses have been described previously (Springer et al. 1992).

\section{RNA blot analyses}

RNA was prepared and blotted according to the protocol of Sachs and Yanofsky (1991), with the exception that cells were disrupted using a mini-beadbeater.

\section{Scanning electron microscopy}

Scanning electron microscopy and sample preparation were performed as described (Springer 1989; Springer and Yanofsky 1989).

\section{Acknowledgments}

We thank E. Selker, D.D. Perkins, and C. Selitrennikoff for supplying strains; C. Yamashiro for supplying DNA probes; and Holly Goodson, Karl Hager, Frank Lauter, Linda Silveira, and Carl Yamashiro for helpful comments on this manuscript. C.Y. is a Career Investigator of the American Heart Association. This work was supported by grant GM-41296 from the National Institutes of Health.

The publication costs of this article were defrayed in part by payment of page charges. This article must therefore be hereby 
marked "advertisement" in accordance with 18 USC section 1734 solely to indicate this fact.

\section{References}

Berlin, V. and C. Yanofsky. 1985. Isolation and characterization of genes differentially expressed during conidiation of $\mathrm{Neu}$ rospora crassa. Mol. Cell. Biol. 5: 849-855.

Bistis, G.N. 1981. Chemotropic interactions between trichogynes and conidia of opposite mating-type in Neurospora crassa. Mycologia 73: 959-975.

Davis, R.H. and F.J. de Serres. 1970. Genetic and microbiological research techniques for Neurospora crassa. Methods Enzymol. 27A: 79-143.

Dodge, B.O. 1932. The non-sexual and the sexual functions of microconidia of Neurospora. Bull. Torrey Bot. Club 59: 347360.

Grigg, G.W. 1960. The control of conidial differentiation in Neurospora crassa. J. Gen. Microbiol. 22: 662-666.

Hager, K.M. and C. Yanofsky. 1990. Genes expressed during conidiation in Neurospora crassa: Molecular characterization of con-13. Gene 96: 153-159.

Harris, J.L., H.B. Howe Jr., and I.L. Roth. 1975. Scanning electron microscopy of surface and internal features of developing perithecia of Neurospora crassa. J. Bacteriol. 122: 12391246.

Jurgenson, J.E. and S.P. Champe. 1990. The sexual and asexual spores of Aspergillus nidulans contain partially overlapping sets of mRNAs. Exp. Mycol. 14: 89-93.

Lee, K.L., H.R. Buckley, and C.C. Campbell. 1975. An amino acid liquid synthetic medium for the development of mycelial and yeast forms of Candida albicans. Sabouraudia 13: $148-153$.

Lowry, R.J., T.L. Durkee, and A.S. Sussman. 1967. Ultrastructural studies of microconidium formation in Neurospora crassa. I. Bacteriol. 94: 1757-1763.

Mahoney, D.P., L.H. Huang, and M.P. Backus. 1969. New homothallic Neurosporas from tropical soils. Mycologia 61: 264-272.

Perkins, D.D. 1986. Hints and precautions for the care, feeding and breeding of Neurospora. Fungal Genet. Newsl. 33: 3541.

Raju, N.B. 1980. Meiosis and ascospore genesis in Neurospora. Eur. J. Cell Biol. 23: 208-223.

Ricci, M., D. Krappmann, and V.E.A. Russo. 1991. Nitrogen and carbon starvation regulate conidia and protoperithecia formation of Neurospora crassa grown on solid media. Fungal Genet. Newsl. 38: 87-88.

Roberts, A.N. and C. Yanofsky. 1989. Genes expressed during conidiation in Neurospora crassa: Characterization of con-8. Nucleic Acids Res. 17: 197-214.

Roberts, A.N., V. Berlin, K.M. Hager, and C. Yanofsky. 1988. Molecular analysis of a Neurospora crassa gene expressed during conidiation. Mol. Cell. Biol. 8: 2411-2418.

Rossier, C., N. Oulevey, and G. Turian. 1973. Electron microscopy of selectively stimulated microconidiogenesis in wild type Neurospora crassa. Arch. Mikrobiol. 91: 345-353.

Sachs, M.S. and C. Yanofsky. 1991. Developmental analyses of mRNA levels for genes involved in conidiation and amino acid biosynthesis in Neurospora crassa. Dev. Biol. 148: $117-$ 128.

Schägger, H. and G. von Jagow. 1987. Tricine-sodium dodecyl sulfate-polyacrylamide gel electrophoresis for the separation of proteins in the range from 1 to $100 \mathrm{kDa}$. Anal. Biochem. 166: $368-379$.
Selitrennikoff, C.P., R.E. Nelson, and R.W. Siegel. 1974. Phasespecific genes for macroconidiation in Neurospora crassa. Genetics 78: 679-690.

Soll, D.R. 1986. The regulation of cellular differentiation in the dimorphic yeast Candida albicans. BioEssays 5: 5-11.

Springer, M.L. 1989. An effective procedure for the preparation of Neurospora conidiophores for scanning electron microscopy. Fungal Genet. Newsl. 36: 78.

Springer, M.L. and C. Yanofsky. 1989. A morphological and genetic analysis of conidiophore development in Neurospora crassa. Genes \& Dev. 3: 559-571.

Springer, M.L., K.M. Hager, C. Garrett-Engele, and C. Yanofsky. 1992. Timing of synthesis and cellular localization of two conidiation-specific proteins of Neurospora crassa. Dev. Biol. (in press).

Tan, S.T. and C.C. Ho. 1970. A gene controlling the early development of protoperithecium in Neurospora crassa. Mol. (4) Gen. Genet. 107: 158-161.

Timberlake, W.E. 1980. Developmental gene regulation in Aspergillus nidulans. Dev. Biol. 78: 497-510.

Turian, G. and D.E. Bianchi. 1972. Conidiation in Neurospora. Bot. Rev. 38: 119-154.

Vogel, H.J. 1964. Distribution of lysine pathways among fungi: Evolutionary implications. Am. Nat. 98: 435-446.

Wilson, C.H. 1985. Production of microconidia by several $f 1$ strains. Neurospora Newsl. 32: 18. 


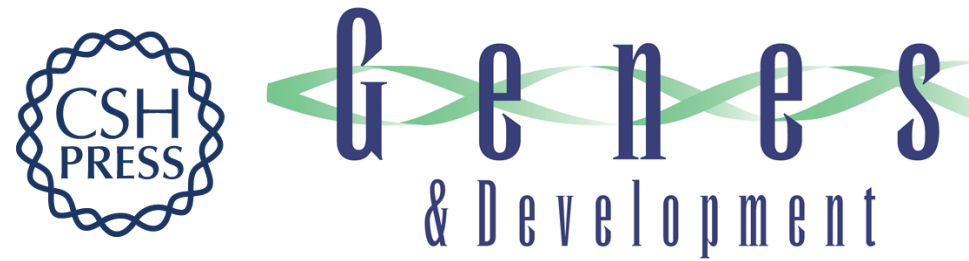

\section{Expression of con genes along the three sporulation pathways of Neurospora crassa.}

M L Springer and C Yanofsky

Genes Dev. 1992, 6:

Access the most recent version at doi:10.1101/gad.6.6.1052

References This article cites 28 articles, 6 of which can be accessed free at:

http://genesdev.cshlp.org/content/6/6/1052.full.html\#ref-list-1

License

Email Alerting

Service

Receive free email alerts when new articles cite this article - sign up in the box at the top right corner of the article or click here.

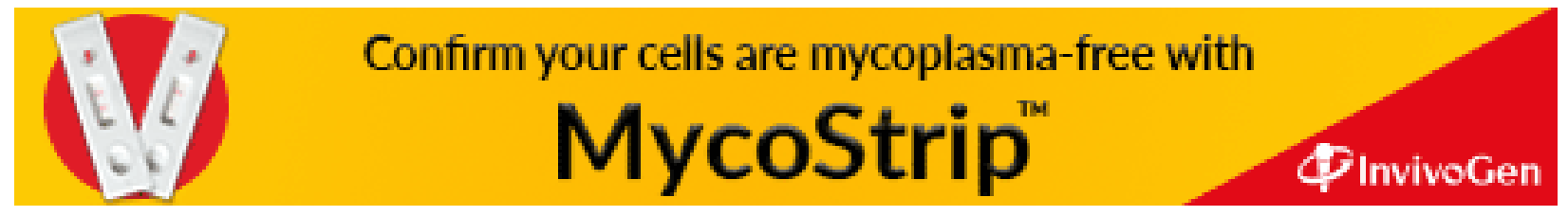

